Borneo Journal of Sciences \& Technology, 4(1): 37-43

DOI: http://doi.org/10.3570/bjost.2022.4.1-06

e-ISSN: 2672-7439

(C) 2018, UTS Publisher.

Submitted: $16^{\text {th }}$ November $2021 \quad$ Accepted: $20^{\text {th }}$ December $2021 \quad$ Published: $31^{\text {st }}$ January 2022

\title{
Light Intensity and Temperature Parameters Study for Solar-powered Internet of Things to Improve Photovoltaic Energy Harvest
}

\author{
${ }^{1}$ Kim-Mey Chew, ${ }^{2}$ Syvester Chiang-Wei Tan \\ ${ }^{1}$ University of Technology Sarawak, 96000 Sibu, Sarawak, Malaysia \\ ${ }^{2}$ Universiti Malaysia Sarawak, 94300 Kota Samarahan, Sarawak, Malaysia
}

\begin{abstract}
The Internet of Things (IoT) is an emerging technology that provides inter-device connectivity and is widely used in today's world. Maintaining battery life is one of the challenges of the technology mentioned and solar energy appears to be the solution. Solar energy is the conversion of energy from the sun to electricity, either directly with photovoltaic (PV), indirectly with concentrated solar energy, or a combination of both. In order to get the best out of photovoltaic energy, the development focus on improving the efficiency of the solar panels used. The variation in the intensity of sunlight contributes to a significant reduction in efficiency. The study aims to investigate the effect of light intensity and temperature parameters on the photovoltaic energy harvest. In this study, the light intensity was measured with a light-dependent resistance (LDR) sensor module. The analog output of the LDR sensor module was converted by the microcontroller to the digital output and computed using the voltage-resistanceintensity equation for the luminous intensity in lux. The solar efficiency towards the temperature was calculated based on the temperature coefficient of the solar panel used to identify the maximum output power. The solar panel efficiency graph providing insights into the maximum power that can be generated at a particular temperature. The study proves that the light intensity and temperature parameters make photovoltaic energy harvesting more efficient.
\end{abstract}

Keywords: Illumination intensity, LDR sensor module, photovoltaic energy, solar efficiency, temperature coefficient

\section{INTRODUCTION}

The focus on digital transformation has encouraged more companies to adopt the invention of the Internet of Things (IoT). At the 2016 World Economic Forum in Davos, Switzerland, the IoT was to be the fourth industrial revolution that would lead to a new age of machines. The IoT is expected to allow for complete digitization of business processes, unprecedented operational efficiencies and disruptive business model innovation [1].

IoT deployment is increasingly diversified, from consumer-based applications to mission-critical applications. Consumer applications referring to intelligent household appliances and wearables. Mission-critical applications range from public safety, industrial automation, autonomous vehicles and the Internet of Medical Objects (IoMT) to emergency response. As these mission-critical applications gain popularity, engineers and designers must consider important design and test considerations and compromise initial design and manufacturing results [3]. The five main design challenges of the IoT were simplified as "5C": Connectivity, Continuity, Compliance, Coexistence and Cybersecurity [4].

Conquering 5C's technical challenges ensures success for the IoT. An extensive understanding of these issues will provide a solid foundation for the implementation and deployment of the IoT system. Proper design and validation will ensure delivery of the IoT. Among the 5C, securing and extending the battery life is one of the most crucial challenges for IoT devices [5]. IoT opens the door to a variety of possibilities by facilitating a sustainable solution to access clean energy. In parallel, the challenges: energy management, sensing, security, complex design and wireless communication [6] needs to be monitored. For seamless integration of devices using the internet into the IoT, energy consumption should be carefully monitored and predicted on an ongoing basis.

\section{LITERATURE REVIEW}

Solar systems are regarded as a key tool in providing energy for current and future generations. A solar cell or photovoltaic cell is a device that transforms solar light into useable energy. The quantity of solar light 


\section{Light Intensity and Temperature Parameters Study for Solar-powered Internet of Things to Improve Photovoltaic Energy Harvest}

that can be converted into electricity is called solar panel efficiency. Certain factors must be taken into account to ensure the maximum efficiency of solar panels.

\section{Solar Photovoltaic (PV)}

The principle of converting solar light into electricity, referred to as photovoltaic (PV) conversion. Solar energy generation relies on the intensity of the solar rays on the solar panel and the wavelength. A photon is characterized by either a wavelength, denoted by $\lambda$ or equivalently an energy, denoted by $\mathrm{E}$. The relation between the photon energy $(E)$ and the wavelength of light $(\lambda)$ given in Equation (1). The challenge of solar energy is to maximize the wavelength of solar rays and minimize the temperature effect on the panel [8].

$$
E=\frac{h c}{\lambda}
$$

where: $h$ (Planck's constant $)=6.626^{*} 10^{-34}$ joules

$$
c(\text { speed of light })=2.998 * 10^{8 \mathrm{~m} / \mathrm{s}}
$$

The PV cell of the solar panel consists of two types of semiconductors charged with different impurities. This leads to an uneven distribution of free electrons ( $n$ type) on one side of the junction and an excess of holes (p-type) on the other side of the junction. The silicon atoms of a photovoltaic cell absorb energy from light wavelengths that roughly correspond to the visible spectrum. Both different impurities in silicon produce positive and negative loads. Light moves the electrons and produces a current. Material containing different impurities charges at different wavelengths. The PV cell does not completely convert the entire light to electrical charge, even if it is at the correct wavelength. Part of the energy becomes heat and part is reflected back on the surface of the cell.

The spectral response is the ratio of the current generated by the solar cell to the electrical event on the solar cell. Figure 1 illustrates a solar cell's spectral response to glass-covered silicon. At short wavelengths of less than $400 \mathrm{~nm}$, glass absorbs most of the light, but the cell response is very low. At intermediate wavelengths, the cell comes close to the ideal, but at long wavelengths, the response reverts back to zero. The ideal spectral response is restricted to long wavelengths by the incapacity of the semiconductor to absorb the photon with energies below the band interval. Any energy higher than the band interval is not used by the solar cell and goes instead to heat the solar cell. The inability to use high energies and the inability to absorb low light energies demonstrated a significant power loss within a single $p-n$ junction solar cell [9].

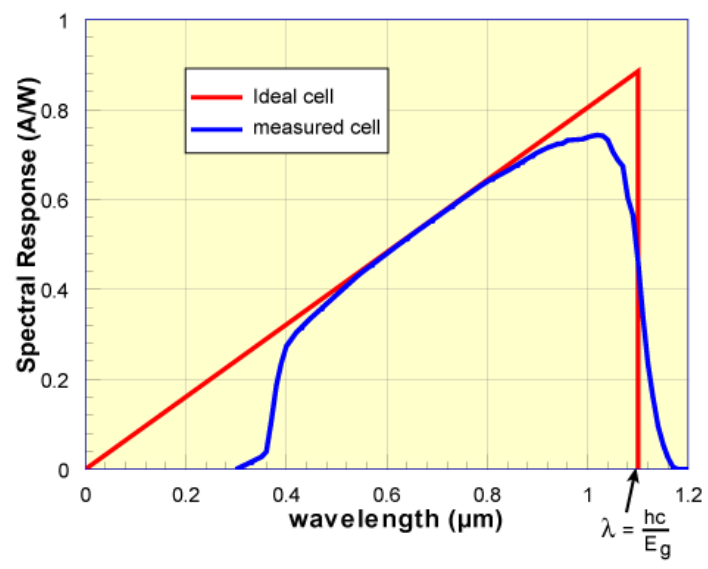

Figure 1: Spectral response of a silicon solar cell under glass [9]

\section{Effect of Temperature on PV Performance}

Under the rules of thermodynamics, heat limits any electronic capacity to produce energy [10]. The rise in temperature decreases the ability of the solar photovoltaic module to produce electricity. Percentage drop in production for each 1 degree Celsius $\left({ }^{\circ} \mathrm{C}\right)$ rise in temperature from $25^{\circ} \mathrm{C}$. Most solar panels have a temperature coefficient in the range of $-0.3 \% /{ }^{\circ} \mathrm{C}$ through $-0.5 \% /{ }^{\circ} \mathrm{C}$. In general, solar panels using monocrystalline and polycrystalline solar cells will have a temperature coefficient between $-0.44 \%$ and $0.50 \%[11] ;[12]$.

Knowing the temperature of a photovoltaic solar panel is important in predicting its output power. It is also important to know the material of the PV panels, as the efficiency of the various materials varies according to the temperature. Therefore, a photovoltaic system should be designed not only according to the maximum, minimum and average environmental temperatures in 


\section{Light Intensity and Temperature Parameters Study for Solar-powered Internet of Things to Improve Photovoltaic Energy Harvest}

each place. As well as understanding the materials used in the PV panel.

\section{Light Intensity}

Illuminance is the measurement used to measure the light intensity in a space, while lumens $(\mathrm{lm})$ are the unit of measurement. Illuminance is the amount of light (lumens) falling on a surface (on a given square foot or square meter) measured in footcandles or lux. Therefore, light intensity is measured in terms of lumens per square foot (footcandles) or lumens per square meter $(l u x)$. Measuring the amount of light that falls on a surface is a measure of whether there is enough light to perform a variety of visual tasks. The higher the lumen output, the brighter or higher intensity the light source. The lower the lumen output, the less bright or lower intensity the light source [13].

With a light source of 1,000 lumens. If all these 1,000 lumens are spread over an area of 1 square meter, there will be an illumination of 1,000 lux. If the lumens spread over 10 square meters the illumination or lux would diminish to a less intense and grader 100 lux. Equation (2) shows the computation of the illumination. Table 1 presents examples of light levels common to the natural light source released by the Illuminating Engineers Society of North America (IESNA).

$$
\text { Illuminance }: E(l x)=\frac{\text { luminous flux }(\mathrm{lm})}{\text { area }\left(m^{2}\right)}
$$

Table 1: Common light levels published by IESNA [14]

\begin{tabular}{|l|c|c|}
\hline \multirow{2}{*}{\multicolumn{1}{c|}{ Condition }} & \multicolumn{2}{c|}{ Light Level } \\
\cline { 2 - 3 } & Footcandles & Lux \\
\hline Bright Summer Day & $\sim 10,000$ & 100,000 \\
\hline Full Daylight & $\sim 1,000$ & 10,000 \\
\hline Overcast Day & $\sim 100$ & 1,000 \\
\hline Traditional Office Lighting & $30-50$ & $300-500$ \\
\hline Common Stairway & $5-10$ & $50-100$ \\
\hline Twilight & 1 & 10 \\
\hline Full Moon & $<0.1$ & $<1$ \\
\hline
\end{tabular}

\section{METHODOLOGY}

The session covers the components, solar panels and the LDR sensor module used for the study to improve the photovoltaic energy harvest of the solar-powered IoT device.

\section{Solar Cell}

The basic measurement of solar panel power generation is calculated by testing the panels under average conditions, known as standard test conditions (STC). The STC measures the power output from the solar panel using common light, orientation and temperature conditions of the panel. At the STC, the power per square meter $\left(\mathrm{W} / \mathrm{m}^{2}\right)$ is $1000 \mathrm{~W} / \mathrm{m}^{2}$. This is the standard used to determine how many watts of power are produced in one square meter on earth.

The efficiency of solar panels is another factor that influences the amount of energy that a specific panel will produce. Panel efficiency refers to the panel's ability to convert sunlight into useable energy. In a panel with $20 \%$ efficiency, $20 \%$ of all incoming light will be converted into electricity. A panel with greater efficiency will convert more sunlight to energy. Most of the solar panels have an efficiency of about 15-18\%. Equation (3) gives the calculation of the solar cell efficiency [15].

However, the actual conditions are usually different from those of the STC, so a typical panel seldom produces its maximum predicted output. Solar panel temperature is seldom constant at $25^{\circ} \mathrm{C}$ (the temperature used to determine STC indices). Most solar panels have a temperature of $20^{\circ} \mathrm{C}$ greater than room temperature. This means that if the outside temperature is $20^{\circ} \mathrm{C}$, the solar panel temperature is likely about $40^{\circ} \mathrm{C}[15]$.

$$
\eta_{\max }=\frac{P_{\max }}{E * A_{c}} x 100 \%
$$

Where : $P_{\max }=$ Maximum Power Output $($ in $\mathrm{W})$

$E=$ incident radiation flux (in $\mathrm{W} / \mathrm{m}^{2}$ )

(*at $S T C=1000 \mathrm{~W} / \mathrm{m}^{2}$ )

$A_{c}=$ Area of Collector (in $\mathrm{m}^{2}$ ) 


\section{Light Intensity and Temperature Parameters Study for Solar-powered Internet of Things to Improve Photovoltaic Energy Harvest}

\section{LDR Sensor Module}

A LDR or light-dependent resistance is also known as photoresistor, photocell and photoconductor. It is a type of resistance that varies with the amount of light falling on its surface. This is a passive component which reduces the resistance to the reception brightness (light) on the sensitive surface of the component.

An analogue output of $5 \mathrm{~V}$ was generated from the LDR sensor module. The analog output of the LDR sensor module was converted by the microcontroller to digital output. As the light intensity is measured in lumens per square foot (footcandles) or lumens per square meter (lux), the voltage-resistance-intensity formula was used to obtain the light intensity in lux. Table 2 [16] shows the simulated light intensity (LDR lux) data in relation to the digital output (LDR intensity) and analog output (output voltage, $V$ ). The voltage-resistance-intensity equation was formulated using the aforementioned simulated data.

Table 2: LDR simulation result [16]

\begin{tabular}{|c|c|c|}
\hline LDR Intensity & Output Voltage (V) & LDR (Lux) \\
\hline 11 & 0.0538 & 0.1 \\
\hline 372 & 1.8174 & 10.1 \\
\hline 520 & 2.5379 & 20.1 \\
\hline 607 & 2.9655 & 30.1 \\
\hline 667 & 3.2545 & 40.1 \\
\hline
\end{tabular}

\section{RESULT AND DISCUSSION}

The session covers the formation of the voltageresistance-intensity equation for the calculation of light intensity in lux. Furthermore, the efficiency of the solar panels of the various monocrystalline and polycrystalline solar cells used was discussed in relation to the effect of temperature on PV performance.

\section{Voltage-Resistance-Intensity Equation}

The voltage-resistance-intensity equation is intended to calculate the light intensity in lux. Lux is the SI-derived illuminator unit, which measures the luminous flux per unit area. This is an equivalent of one lumen per square meter.

Figure 2 shows the linear regression analysis of the output of the analog-to-digital converter (ADC) at a resolution of 10-bits. With the operating voltage of $5 \mathrm{~V}$, the LDR sensor module shows a linear regression of its analog output in relation to the digital light intensity. The dependent and independent variables exhibit a positive relationship with a regression factor of 204.87 and an acceptable constant near $-0.1168 \mathrm{~V}$. The analysis aims to forecast the analog output to obtain a more significant measurement of light in lux.

The voltage-resistance-intensity equation was formed using the trend line with forecast periods of 2.0 applied to the analog output graph relative to the light intensity (Figure 3). The trend line is designed to achieve the dominant direction of light intensity at the maximum $5 \mathrm{~V}$ analog output. Exponential regression indicates the best adjustment of the trend line on the analog output to the light intensity in lux. According to the graph, the maximum light intensity that can be measured with this $5 \mathrm{~V}$ LDR sensor module is about 1699 lux. 


\section{Light Intensity and Temperature Parameters Study for Solar-powered Internet of Things to Improve Photovoltaic Energy Harvest}



Figure 2: Linear regression of voltage (LDR analog output) and light intensity (LDR digital output)

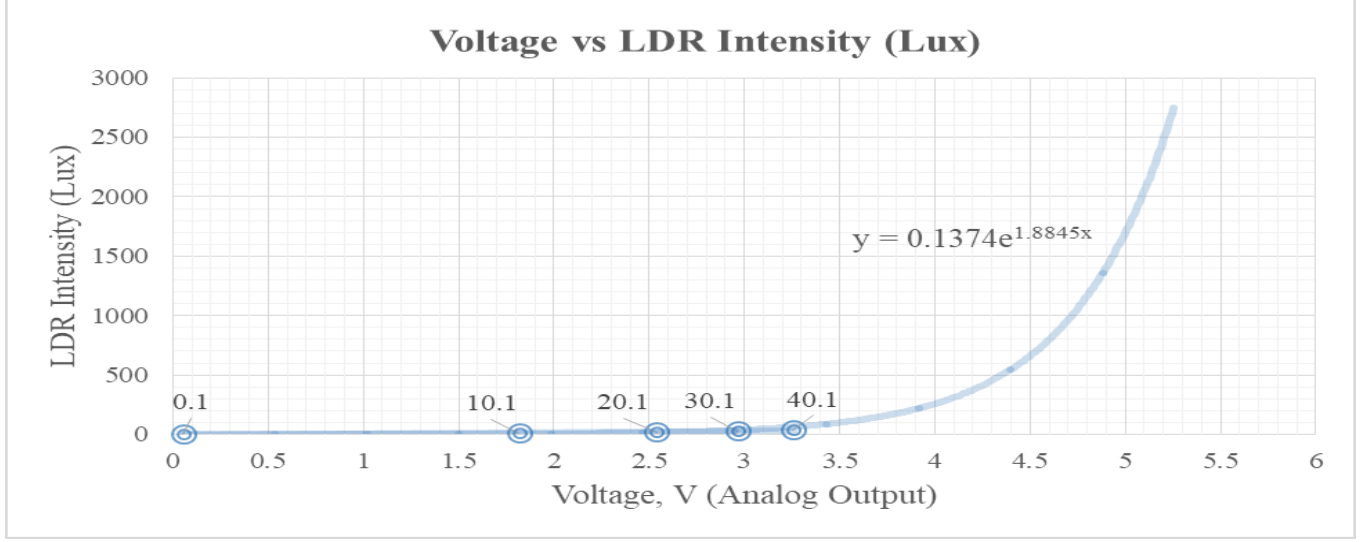

Figure 3: Voltage-resistance-intensity equation based on the voltage (LDR analog output) and LDR in lux

\section{Solar Panel Efficiency}

Table 3 outlines the solar cell specification for the selected panels. Two main types of solar panels were used in this study, monocrystalline and polycrystalline. The solar panels used have an average maximum output of 5 watts. The efficiency (\%) of the chosen solar panel was computed using equation (2). Solar panels were studied on the basis of their efficiency based on the temperature coefficient with the rise in temperature. The solar panel efficiency is important to determine the performance of the panel.

\section{Temperature Coefficient}

Solar panels undergo maximum power testing at an industry standard temperature of $25^{\circ} \mathrm{C}$. Typically, solar panels will begin to generate less energy when the temperature exceeds $25^{\circ} \mathrm{C}$. The "temperature coefficient" refers to the percentage of output power that is lost by a specific solar panel as the temperature rises above $25^{\circ} \mathrm{C}$. According to research studies [11, 12], monocrystalline and polycrystalline solar cells have a temperature coefficient ranging from $-0.44 \%$ to $0.50 \%$. Assume that the selected solar panel has a minimum temperature coefficient of $-0.44 \%$. The performance of the solar panels was estimated in correlation with the calculated efficiency (\%) of solar cell in Table 3 and the outcome was illustrated in Figure 4.

With a similar panel size (Type A \& B), the monocrystalline solar cell has a better efficiency compared to the polycrystalline solar cell. As solar panels increased in size (Type B, Type C and Type D), solar efficiency gradually diminished. Research [15] shows that most solar panels have a temperature $20^{\circ} \mathrm{C}$ higher than the ambient temperature. This means that if the outdoor temperature is $20^{\circ} \mathrm{C}$, the temperature of the solar panel is probably around $40^{\circ} \mathrm{C}$. Assuming that the outside temperature is $32^{\circ} \mathrm{C}$, the solar panel temperature is likely to be approximately $52^{\circ} \mathrm{C}$. In this case, Type $\mathrm{C}$ and Type $\mathrm{D}$ solar cells are difficult to operate. Types A and B may still function, but with very low energy output. At $62^{\circ} \mathrm{C}$, none of the solar panels on offer are suitable for use. 
Light Intensity and Temperature Parameters Study for Solar-powered Internet of Things to Improve Photovoltaic Energy Harvest

Table 3: Solar cell specification

\begin{tabular}{|c|l|c|c|c|c|}
\hline Type & \multicolumn{1}{|c|}{ Solar Panel Type/Material } & $\begin{array}{c}\text { Maximum } \\
\text { power }(\mathbf{W})\end{array}$ & $\begin{array}{c}\text { Working } \\
\text { voltage }(\mathbf{V})\end{array}$ & $\begin{array}{c}\text { Size } \\
(\mathbf{c m})\end{array}$ & $\begin{array}{c}\text { Efficiency } \\
(\boldsymbol{\%})\end{array}$ \\
\hline A & Polycrystalline silicon Epoxy & 5.2 & 12 & $21 * 16.5$ & 15.0 \\
\hline B & Monocrystalline silicon Epoxy Laminated & 5.3 & 6 & $15.5 * 21$ & 16.3 \\
\hline C & Monocrystalline & 5.0 & 12 & $26 * 16.5$ & 11.7 \\
\hline D & Monocrystalline & 5.0 & 12 & $29 * 17.5$ & 9.9 \\
\hline
\end{tabular}



Figure 4: Solar panel efficiency with the increment of temperature

\section{CONCLUSION}

The LDR sensor module may be used for measuring light intensity with a maximum of 1699 lux. This shows the limitation of the sensor used whereas the maximum lux may reach 100000 lux during a summer day. The study found that the monocrystalline solar cell is more effective than the polycrystalline solar cell. Moreover, the increase in the size of solar cells does not promise better efficiency of solar panels than if the increase in maximum power produced. It indicates the rise in voltage and ampere on the solar panel. Lowering the temperature of the solar cell might be another solution to increase the efficiency of the solar cell. These findings permit a more precise selection of solar panels in youth development based on the correlation between light intensity and temperature towards PV performance. This study will be continued and practically carried out to obtain experimental data with a view to further verification and justification.

\section{ACKNOWLEDGEMENT}

The authors would like to express the gratitude to the University of Technology Sarawak (UTS) for supporting and funding this study under Research Grant (UCTS/RESEARCH/4/2019/12)

\section{REFERENCES}

[1] IoT \& Customer Innovation Unit. (2016, Sept). IoT Drives Digital Transformation. ICT Insights Newsletter. Retrieved from https://e.huawei.com/my/publications/global/ict_in sights/201711060837/solutions/201712121546.

[2] Ahmad, S., Mehmood, F., \& Kim, D. H. (2019). A DIY Approach for the Design of Mission-planning Architecture Using Autonomous Task-object Mapping and the Deployment Model in Missioncritical IoT Systems. Sustainability, 11(13), 3647.

[3] Wong, S. H. (2020, June). The Top Five Challenges of IoT. IoT Feature Newsletter. Retrieved from https://www.iotevolutionworld.com /iot/articles/445866-top-five-challenges-iot.htm 


\section{Light Intensity and Temperature Parameters Study for Solar-powered Internet of Things to Improve Photovoltaic Energy Harvest}

[4] Jolly, B. (2021). IoT Device Battery Life: Go Slow for Fast Insights Into Challenging Conditions. In 2021 IEEE International Midwest Symposium on Circuits and Systems (MWSCAS), pp. 680-683.

[5] Chew, K. M., Yiiong, S. P., Bundan, N., Loh, G. C. W., \& Tan, S. C. W. (2020). Internet of Things (IoT) Continuity Challenge: Green Energy Power Consumption. IEEE International Conference on Sensors \& Nanotechnology 2021, pp. 1-5.

[6] Chen, Y. K. (2012). Challenges and Opportunities of Internet of Things. In IEEE 17th Asia and South Pacific design automation conference, pp. 383388.

[7] Kumar, M. N., Saini, H. S., Anjaneyulu, K. S. R., \& Singh, K. (2014). Solar Power Analysis Based on Light Intensity. The International Journal of Engineering and Science, 01-05.

[8] Tudorache, T., \& Kreindler, L. (2010). Design of a Solar Tracker System for PV Power Plants. Acta Polytechnica Hungarica, 7(1), 23-39.

[9] Honsberg, C.B. and Bowden, S.G. (2019). Photovoltaics Education Website. https://www.pveducation.org/

[10] Atkins, P. (2010). The Laws of Thermodynamics: A Very Short Introduction. OUP Oxford.
[11] Surles, W., Baum, J., Watrous, A., Johnson, S., Horanyi, E., \& Zarske, M. S. (2009). Photovoltaic Efficiency Lesson 2 The Temperature Effect. Regents of the University of Colorado. Retrieved from: https://www. teachengineering. org/collection/cub_/lessons/cub_pveff/Attachments /cub_pveff_lesson02_fundamentalsarticle_v6_tedl dwc. pdf.

[12]Cotfas, D. T., Cotfas, P. A., \& Machidon, O. M. (2018). Study of Temperature Coefficients for Parameters of Photovoltaic Cells. International Journal of Photoenergy, vol. 2018, 12 pages.

[13] Illuminating Engineering Society of North America. (2000). Lighting Handbook: Reference \& Application. Illuminating Engineering Society of North America.

[14] Mark, S. (2000). The IESNA Lighting Handbook. Reference \& Application, 9.

[15] Belghachi, A. (2015). Theoretical Calculation of the Efficiency Limit for Solar Cells. Solar CellsNew Approaches and Reviews.

[16] Jumaat, S. A., \& Othman, M. H. (2018). Solar Energy Measurement Using Arduino. In EDP Sciences MATEC web of conferences. vol. 150, p. 01007. 